\title{
THE LAW OF ONE PRICE AND ARBITRAGE ON CHINA'S DUAL-LISTINGS IN HONG KONG AND NEW YORK
}

\author{
Liu, Lixian and Timofei Bogomolov \\ University of South Australia
}

\begin{abstract}
Traditionally, arbitrage refers to simultaneously buying and selling the same financial assets by taking advantage of a price difference in two or more markets. However, the strict sense of arbitrage is hardly obtained after consideration the issues concerning transaction costs and time value of money. By using the identical assets such as Chinese ADRs and their underlying securities traded in different markets in Hong Kong in HK dollar and in New York in US dollar and by constructing a very simple arbitrage trading strategy, this study demonstrates that arbitrage profits are still available with monthly return ranging from 0.5 per cent to 3.8 per cent after considering transaction costs and non-overlap trading time issues. This is a new study to verify this behaviour of an emerging market's ADRs traded in two financial market locations, so adding evidence of inefficiency in trading of China-listed stocks in foreign locations.
\end{abstract}

Key Words: Arbitrage, Transaction costs, ADRs, Financial markets, Trading strategy

JEL Classification: G10, G19, C18

\section{Introduction}

Theoretically, Law of One Price (LOP) states that securities traded as cross-border transactions in different currencies - for example the securities located in China and traded in Hong Kong and in the US in the form of American Depository Receipts (ADRs) - should have identical prices given the ease with which arbitrage could be conducted across markets. Therefore, it is claimed, all securities are close substitutes for investors in that investors would price these securities identically. The price disparity idea is readily confirmed for some of the dual-listed Chinese securities that are traded in both Hong Kong and New York markets although Malkiel 
(2007) states that H-shares and N-shares (Chinese shares listed and traded in Hong Kong and New York markets respectively) are reasonably priced relative to their growth rates.

Since Chinese ADRs (American Depository Receipts) can be freely converted to $\mathrm{H}$ shares, arbitrage should force the prices of these Chinese securities in the New York Stock Exchange and Stock Exchange of Hong Kong to reach equilibrium. If the Hong Kong (HK) and New York (NY) markets are integrated in terms of the trading of cross-listed securities, the close price in Hong Kong and the open price in NY for those cross-listings should not exhibit any exceptional levels of volatility, volume or spreads regarding the trading activity (Domowitz et al. 1998).

This study investigates the price disparity between these dual-listed Chinese securities and explores if there is arbitrage opportunities for traders meaning that the prices are identical. Most of the dual-listed Chinese securities traded in the HK and NY markets also have their shares traded in the Mainland China market. Since the short selling and free capital flows are restricted in the Chinese mainland stock markets, does the arbitrage idea still hold is an unanswered policy issue. Hence the examination on the arbitrage opportunities in this set up is of research interest so we focus on the dual-listed Chinese securities traded in HK and NY markets in the form of ADRs.

The rest of the paper is organised into four sections. A brief review of literature is attempted to show that there is very little consensus that there is arbitrage-free trades in the cases of dual-listed Chinese shares despite there being evidence of no arbitrage profits in trades of dual-listed shares in developed markets. In the following section, we provide a description of the data and research process to estimate share price returns adjusted for currency and for transaction costs in Hong Kong and New York of the China shares. The results are presented in section 4 while the paper is concluded in section 5 . There is evidence of 0.5 per cent or more arbitrage profit opportunities in trades of 14 China shares.

\section{Review of Arbitrage Literature on Dual Listings}

There is no consensus in the literature regarding the price discrepancy and arbitrage of the crosslisted securities. The existing studies present different views on cross-listing and arbitrage. Maldonado and Saunders (1983), Kato et al. (1991), Park and Tavakkol (1994), Ding (2000), and Lok and Kalev (2006) found no significant price disparity between the cross-listed shares. 
So they suggest no obvious arbitrage opportunities exist. In contrast, Wahab, Lashgari and Cohn (1992), Kaul and Mehrotra (2000) and Suarez (2005) did find arbitrage opportunities. Bailey et al. (1999) and Miller and Morey (1996) found price differences, but suggested that arbitrage is difficult.

Maldonado and Saunders (1983) examine the one-year price behaviour of 37 US multinational corporation stocks traded simultaneously on the London and New York Stock exchanges under the restricted and unrestricted periods of the British Investment controls. Their empirical results strongly supported LOP for internationally traded stocks after adjustment for exchange rates and transactions costs. Note that these markets do not frictions in terms of restriction in trades or even ownership. They also suggested that LOP is not violated even under a one-sided government that imposes foreign exchange restriction on trade.

Wahab et al. (1992) studied arbitrage between ADRs and their underlying stocks using an implicit pairs trading strategy with two portfolios: one is ADR, the other is underlying home shares portfolio. They sell the winner (portfolio with the highest return over a period of two weeks) and buy the loser (portfolio with the lowest returns over the same two-week period). They found limited profits for their pairs-trading strategy when about four per cent transaction costs were considered and data limitations overcome.

Miller and Morey (1996) examined one of the most heavily traded British stock (GlaxoWellcome) that is cross-listed in the US using intraday data to test arbitrage on European ADRs: they also investigate the intraday price difference pattern between ADRs and the underlying securities. The results showed that the price difference in these two markets was small and insignificant throughout their two-month sample period, suggesting the market is efficient with respect to arbitrage opportunities.

Ding (2000) examined the cross-listed stocks that were traded on the Stock Exchange of Singapore and the Kuala Lumpur Stock Exchange (now called Bursa Malaysia) to see if the two markets are closely linked and the price parity is maintained from the same Malaysian stock traded on both the Kuala Lumpur Stock Exchange and Singapore's CLOB International. ${ }^{1}$ The results showed that the two markets were well linked in terms of their returns and volatility. The

\footnotetext{
${ }^{1}$ In the Stock Exchange of Singapore and the Kuala Lumpur Stock Exchange, stocks were cross-listed and traded on both exchanges in their local currencies. However, on 1 January 1990, the cross-listing arrangement was abolished. To facilitate Singaporean investors to trade in Malaysian shares and other foreign shares and to keep the business in Singapore, the Stock Exchange of Singapore set up an over-the-counter market known as CLOB International.
} 
markets of Singapore and Kuala Lumpur also conformed to the law of one price reasonably. Arbitrage opportunities appeared to exist when stock-broking houses trade for their own accounts, obviously with no transaction costs. Meanwhile, arbitrage opportunities for other type of investors were significantly diminished due to their high transaction costs.

Conversely, some of the stock markets have different trading hours, suggesting that two closing prices must not be equal. A number of studies on LOP had results that cannot reject the hypothesis of arbitrage-free pricing because the cross-listed stocks are indeed one security mainly using daily closing prices with non-overlapping trading time (Maldonado and Saunders 1983; Kato et al. 1991; Park and Tavakkol, 1994). Regarding the trading time issue, some of the studies focus on the overlap of trading activities and concluded with that arbitrage opportunities do exist.

De Jong et al. (2007) evaluated a simple trading rule involving a long position in the relatively underpriced part of the twin shares and shorting an equal dollar amount in the relatively overpriced part of the twin shares. They found that this rule produced an abnormal return of up to almost 10 per cent per annum adjusted for systematic risk, transaction costs, and margin requirements. ${ }^{2}$

Suarez (2005) analysed the price disparity between the ADRs and their corresponding French stocks and US companies cross-listed in France using high frequency intra-daily data sets as well as the intra-daily French franc/US dollar exchange rates. The sample included top 10 companies that are extensively traded stocks in both markets. This comparison was done on a 1.5 hours overlap of trading day, when both markets were open. All possible transaction costs were taken into account, and the quotes data rather than traded data were used. The result showed that there was a large deviation from LOP, suggesting that an arbitrage trading profits could be made on these large disequilibria. ${ }^{3}$ Suarez also asserts that these markets were disintegrated and not fully efficient as measured by a lack of arbitrage opportunities.

\footnotetext{
${ }^{2}$ A twin share is also called Siamese twin, which involves two companies incorporated in different countries contractually agreeing to operate their businesses as if they were a single enterprise, while retaining their separate legal identity and existing stock exchange listings. From this sense, it is lightly different from cross-listing. A wellknown example is Royal Dutch/Shell. The shares of the Siamese twin parents represent claims on exactly the same underlying cash flow (Froot and Dobora 1999; Bedi et al. 2003; De Jong et al. 2007).

3 Suarez's paper established a point estimate for the no-arbitrage band of \pm 0.563 per cent, inside which a mispricing cannot be profitably arbitraged due to transaction costs and foreign exchange risk. About 2.1 per cent of the observations in their sample were outside this band and they were thus classified as arbitrage opportunities.
} 
Alves and Morey (2003) examining eleven most traded Brazilian ADRs listed on the New York Stock Exchange used intraday quote price data and the realis/dollar exchange rate, taken on an intraday basis during the period when the two stock markets overlap over a onemonth period in 2001. The transaction costs for different type of investors were also considered for the arbitrage possibilities. The results showed that there seems to be little arbitrage opportunities for the ordinary traders due to higher transaction costs. However, for the Brazilian financial institution, the result showed that there was a profitable arbitrage opportunity available, which the researcher attributed to the special tax laws for financial institutions. Kaul and Mehrotra (2000) studied cross-listed Canadian stocks that were traded in US markets and found that infrequent arbitrage opportunities did exist there, particularly with stock pairs that present a combination of relatively low spreads and low trading volume.

\section{Chinese ADRs and Arbitrage}

A split-share system has existed in China stock market since the re-establishment of stock market in the early 1990s, which allows Chinese companies to issue different classes of shares to domestic and foreign investors. This is an attempt in the earlier days to force foreigners to bring foreign currency money to buy local shares. Only these Chinese firms with the best financial integrity and corporate governance are permitted to be dually listed on the Stock Exchange of Hong Kong as H-shares (named the red chips). In the United States, if listed and traded as ADRs, it is an easy way for an American traders in the US to invest in a foreign company (Mak et al. 2005). H-shares and their related shares traded in New York are essentially shares of mainland Chinese companies registered in Mainland China or HK and traded both on the Stock Exchange of Hong Kong and the New York Stock Exchange, respectively trading in HK Dollar and US dollar. However, under the currency board arrangements, HK dollar is fixed to the US dollar. Therefore the exchange rate risk in this case might be very limited.

It can be observed that the prices of Chinese shares listed in HK are different from their ADRs listed in the US. Several reasons might cause this price discrepancy. The time difference between trading hours in HK and the US might cause different valuation of the shares (Hsu and Wang 2008). Market news and sentiments might be other factors that are responsible for the phenomenon of price discrepancy. The price differences between different markets make the arbitrage activity to take place (Han 2004). 
If there is no time issue, Chinese ADRs traded during HK market hours offer a live arbitrage opportunity as there is very little risk in such trading and the gap between the ADRs and underlying stock is minimal (Hsu and Wang 2008). If there is a spread between the perceived values in the two markets, arbitrage can be expected. If the ADR is trading at a value lower than what the underlying is in Hong Kong market, one can purchase the ADR and expect to make money as its value converges, and vice versa.

\section{Examining Arbitrage Opportunities}

\subsection{Data Collection}

To overcome the time difference between HK and New York, and following Lau and Diltz's (1994) methods, the closing price of each listing in HK and the opening price of each listing in New York are recorded for analysis of evaluation. For the price comparison, all the stock prices are adjusted for exchange rates with denominated HK dollar, which is calculated by multiplying the stock prices in one market with the country's exchange rate, and the ratio of the ADR is considered. All the data used for analysis, including the opening, closing price, foreign exchange rate are obtained from Datastream. In this study, a total of 14 Chinese ADRs and their underlying securities are examined, because only these 14 dual-listed Chinese securities satisfy the requirement to conduct the arbitrage activity, for example, no short selling restrictions.

The data covers the period for each individual company from the same trading date (the listing date for Chinese securities listed in Hong Kong and in New York it is the different for most of the cases) in the HK and New York markets through to 31 December, 2008. This covers the years from 1993 to 2008. Therefore, the data period for each company may be different from each other. The day when shares traded in the HK market but not in the New York market was eliminated from the dataset.

\subsection{Transaction Costs Involved in Arbitrage}

To examine arbitrage possibilities, transaction costs are important factors to influence the arbitrage decision. These transaction costs create a no-arbitrage band, therefore, the arbitrage opportunity must be sizeable enough to generate a profit that could cover and exceed the costs involved. Not all the misprised securities have the profitable arbitrage opportunities. This study 
examines whether arbitrage opportunities exist for China-based stocks traded in the New York market as ADR and in the HK market when transaction costs are considered.

The transaction costs structure faced by each category of investors is significantly different from each other. These differences can affect the magnitude of profits that they can reap from arbitraging. The transaction costs to an investor in different markets can largely consist of several elements, including brokerage fees, clearing fees, stamp duty, and foreign exchange cost. Arbitrage between the Chinese ADRs and their underlying securities may present transaction costs arrived during the process of buying the issue, selling the issue at the existed ADR market, or creating or cancelling the ADRs. According to Citibank, the cost of creating an ADR is four US cents per ADR, and the cost of cancelling an ADR is five US cents per ADR. These costs such as foreign exchange conversion fee, stamp duty can also be significant.

Table 1 presents a list of the related transaction costs when buying or selling the Chinese ADRs and their underlying securities.

\section{Table 1: Computation of Transaction Costs}

This table provides the related transaction costs when trading Chinese ADRs in HK market and their underlying shares in New York market based in 2009.

When the transaction is initiated in $\mathrm{HK}$

\begin{tabular}{lr}
\hline ADR conversion fee & US\$0.05 per ADR \\
Stamp duty on stock transaction & $0.10 \%$ \\
Foreign exchange rate fee & $0.01 \%$ \\
Brokerage fee at NY market & $0.10 \%$ \\
CCASS fee & $0.01 \%$ \\
Custody fee & Free \\
\hline
\end{tabular}

When the transaction is initiated in NY

\begin{tabular}{lr}
\hline ADR conversion fee & US\$0.05 per ADR \\
Foreign exchange rate fee & $0.01 \%$ \\
Brokerage fee at HK market & $0.25 \%$ \\
Custody fee & Free \\
\hline
\end{tabular}

In studying the arbitrage opportunities with transaction costs, this process focuses on one typical type of investors that are likely to be involved in cross-border arbitrage activities. This type of investors could be institutional investors such as stockbroking houses, banks and Qualified Foreign Institutional Investor. It is expected that institutional investors have much lower transactions costs than an ordinary trader. 
The transaction cost in the arbitrage is defined as $c$, which is also the no-arbitrage band for the arbitrage activity when risk is assumed to exist. According to the transaction costs based in 2009 as presented in Table 1, it is assumed that all of the transaction costs are 25 basis points for both markets of HK and New York: there is a five cents ADR subscription and cancellation fee applying in New York. Therefore, the estimated total transaction cost for one deal is assumed to be 0.5 per cent, and 1 per cent for opening and closing one transaction. However, transaction costs are not constant. Stock exchanges change transaction costs from time to time. To overcome the changes in transaction costs in different periods, the arbitrage trading strategy in this study only focus on the period between 2002 and 2008, when there were no changes to the transaction fee.

\subsection{Trading Strategy}

Direct arbitrage between dual- listed Chinese securities traded in HK and New York is impossible as trading hours in New York and HK stock exchanges do not overlap. The time gap between two legs of the trade brings some degree of uncertainty into the trading, and the trade over the pairs of Chinese ADRs in New York and underlying shares in HK executed by the right trading signals of prices divergence and convergence can result in loss.

However, an idea of applying arbitrage-style trading rules still looks very attractive as there are two freely traded assets over the same underlying stock and it is expected that any possible mispricing will be fixed over time. We take log prices of the stocks in HK and ADRs in New York and create a spread process also as price premium as:

$$
\text { spread }=\log P_{t}^{\text {New York }}-\log P_{t-1}^{H K}
$$

Where

$P_{t}^{\text {New York }}{ }_{j} P_{t}^{H K}$ are prices denominated in the same currency (HK dollars) in New York and Hong Kong; $t$ and $t-1$ represent a time difference between New York and HK prices, in this case, $t-1$ is the HK market closing time; $t$ is the same day New York market opening time.

If the difference between prices is greater than a chosen trigger level $\Delta$, we open position on the spread towards zero - initiate a sequence of trades over the pair of stocks in HK and New 
York. When the spread hits zero in the first time we close position on the spread - initiate a sequence of trades to liquidate all open positions over the pair of stocks.

So, if the spread is positive and greater than $\Delta$, we sell short ADRs in New York market and commit ourselves to buy equal volume of shares in HK market regardless any possible price changes. When the spread gets negative for the first time we unwind position on the spread buy ADRs in New York and commit ourselves to sell shares in HK. The expected return from this trading strategy can be estimated as:

$$
\mathrm{E}\left[\log P_{t+n}^{1}-\log P_{t+n-1}^{2}+\varepsilon_{t+n}-\left(\log P_{t}^{1}-\log P_{t-1}^{2}+\varepsilon_{t}\right)\right]=\Delta+2 \mathrm{E}\left[\varepsilon_{t}\right]=\Delta
$$

where: $P_{t}^{1}, P_{t}^{2}$ are shares and ADRs prices denominated in the same currency in HK and US; $\varepsilon_{t}$ - an error term due to the time difference between execution trades, which can be assumed independent and identically distributed with mean zero; $\Delta$ is a trigger level to generate a trading signal to open position on the spread. In fact the expected return is greater than $\Delta$. We trade in discrete manner and value of the spread between shares and ADRs is very unlikely to be equal to $\Delta$ or zero at any point of time $t$. Trading signal to open or close position on the spread will be generated with some overshot.

Trading in the arbitrage style suggests that we will have a positive expected return in each trade, so we want to trade as often as possible to generate more profits. However we have to be sure that the expected profit from each trade is not less than the transaction costs. Transaction costs are reported to reduce profitability dramatically under arbitrage and pairs trading strategies (Bowen et al. 2010; Do 2009).

We estimate transaction costs for the round trip trading over the dual-listed securities in HK and New York as 1 per cent and choose two trigger levels $\Delta$ : 0.01 and 0.02 . The greater trigger level increases the expected return in each trade but reduces number of trades, which reduces the total profit from the trading strategy. 
Since there is a time issue, we consider four scenarios in this study which examines the most logical way to organise trading in two markets with not overlapping working hours:

1. Analyse market and make trading decision on New York market open based on known HK close and New York open. Trade according to trading signals to open/close position on spread at New York open and HK open next day;

2. Analyse market and make trading decision on US market close based on known HK close and New York close. Trade according to trading signals to open/close position on spread at New York close and HK open next day;

3. Analyse market and make trading decision on HK market open based on known New York close of the previous day and HK open. Trade according to trading signals to open/close position on spread at HK open and New York open same day; and

4. Analyse market and make trading decision on HK market close based on known New York close of the previous day and HK close. Trade according to trading signals to open/close position on spread at HK close and New York open same day.

If the market in New York or HK is closed due to holidays, then we do not use those days in our analysis. So no trades can be done on those days even if there is a trading signal to open or close position on the spread.

\subsection{Excess Return Computation}

Following an approach widely used in the literature on contrarian strategies and pairs trading, we trade the same amount of HK\$1 in each short and long position and the total payoff of this strategy has the interpretation of excess return (Gatev et al. 2006).

Daily returns are not calculated as the results could be misleading due to the time differences between the two markets. However, the total payoff after the closing of the last position would be computed as:

$$
p=\left(\log \frac{P_{c}^{1}}{P_{o}^{1}}-\log \frac{P_{c}^{2}}{P_{o}^{2}}\right) I
$$

where: $P_{o}^{1}, P_{o}^{2}$ are the opening prices on securities in HK and New York; $P_{c}^{1}, P_{c}^{2}$ are the closing prices on securities in $\mathrm{HK}$ and New York; $I$ is a dummy variable equals to 1 if we have long 
position on security 1 and short on security 2 and equals to -1 if we have short position on security 1 and long on security 2.

The average holding time is less than three days and there are 14 companies traded simultaneously with average number of trades varying from 10 to 80 per month, so the resulting average total monthly payoff is then divided by the number of companies. The resulting number could be considered as a good estimation of monthly return.

It is necessary to mention that the above method uses leverage 2:1, so the investor should be very careful comparing its results with the performance of the non-leveraged strategies as in a naive buy-and-hold strategy.

We run tests for each trading scenario twice - without transaction costs and with transaction costs, which are estimated to be 1 per cent in total for the round trip. To account the transaction cost we reduce the total payoff of the each arbitrage trade by 1 cent. It's a pretty rough estimation, trading on booming market attracts higher level of transaction costs while trading on falling market costs less. However, as we made reasonably conservative estimation about the size of transaction costs, we believe this simplified approach could provide an adequate representation of the effect of transaction costs on the performance of the proposed trading strategy.

\subsection{Empirical Results}

Table 2 is a summary of descriptive statistics on the daily price premium or discount series for all the 14 Chinese dual-listed securities that are traded in both Hong Kong and New York

The table shows that Chinese ADRs take a relatively higher premium up to 63.3 per cent and discount down to -32.14 per cent during the examined period. These entire 14 price premium series exhibit a low dispersion level with modest standard deviation of one per cent to two per cent; that is, most of the price premium series are near their mean value. The excess kurtosis for all the price premium series are high, suggesting that there could be some extreme observations that lie at the tail of the distribution. 


\section{Table 2: Descriptive Statistics of Daily Price Premium/Discount Dual-Listed Stocks}

This table reports the descriptive statistics of daily price premium or discount for 14 Chinese ADRs and their underlying shares between $1^{\text {st }}$ January, 1993 and $31^{\text {st }}$ December, 2008. The price premium or discount is computed as:LN $\left(\frac{P_{\text {Hong Kong , t }}}{P_{\text {New York, }}}\right)$.

\begin{tabular}{lcccccccc} 
& Mean & St.Dev. & Skewness & Kurtosis & Min & Max & Range & Observations \\
\hline Aluminum & -0.0010 & 0.0143 & -0.2555 & 9.5458 & -0.1013 & 0.0960 & 0.1973 & 1759 \\
China Eastern & -0.0001 & 0.0270 & -1.1243 & 13.3878 & -0.3214 & 0.1634 & 0.4848 & 2796 \\
China Life & 0.0008 & 0.0113 & -0.2935 & 6.6334 & -0.0653 & 0.0510 & 0.1163 & 1267 \\
China Mobile & -0.0007 & 0.0118 & -0.1113 & 12.9121 & -0.1075 & 0.0772 & 0.1847 & 2813 \\
China Petro & 0.0011 & 0.0118 & 0.1200 & 5.9273 & -0.0555 & 0.0739 & 0.1294 & 2057 \\
China Telecome & 0.0010 & 0.0104 & 0.4545 & 11.4357 & -0.0593 & 0.0941 & 0.1534 \\
China Southern & 0.0016 & 0.0256 & -1.1575 & 12.1432 & -0.2335 & 0.1226 & 0.3561 \\
China Unicom & 0.0006 & 0.0128 & 0.1792 & 8.1976 & -0.0731 & 0.0992 & 0.1723 \\
CNOOC & -0.0001 & 0.0105 & 0.5690 & 14.5006 & -0.0633 & 0.1187 & 0.1821 \\
Guangshen Railway & 0.0002 & 0.0220 & -0.3079 & 5.8816 & -0.1677 & 0.1146 & 0.2823 & 2137 \\
Hua Neng & 0.0020 & 0.0190 & 0.6819 & 9.3553 & -0.0942 & 0.1347 & 0.2289 & 2753 \\
Petro China & -0.0002 & 0.0108 & 0.3878 & 6.9271 & -0.0466 & 0.0689 & 0.1155 \\
Sinopec Shanghai & 0.0003 & 0.0213 & -0.6574 & 8.3611 & -0.1592 & 0.1142 & 0.2734 & 389 \\
Yanzhou & -0.0012 & 0.0251 & -0.7137 & 12.7324 & -0.2000 & 0.1883 & 0.3884 & 2194 \\
\hline
\end{tabular}

The detailed analysis of each of the 14 dual-listings is shown in Table 3. The summary there suggests that not all companies perform equally well. Some companies generated small but consistent loss through the entire testing period from 2002 to 2008 while other companies (predominantly the company of China Eastern with longer history of trading in New York and HK) demonstrated up to 10 per cent monthly return after transaction costs. More rigorous approach to the selection of the companies based on the past performance could help to exclude potential losers and improve strategy performance even further.

After the examination of individual companies, as in Tables 3 to 6, we provide average monthly returns of the trading strategy for each scenario with two different trigger levels. Trading statistics related to individual trades are also reported. For the entire scenario, statistically significant excess returns from 2.71 per cent to 8.83 per cent before transaction costs are recorded. Average monthly return after accounting for the transaction costs varies from 0.5 per cent to 3.8 per cent, which are statistically significant for all scenarios except for the scenario 3 for trigger level 0.01 (analysis and first trade on New York open). 
Table 3: Individual Company Average Monthly Excess Returns after Transaction Cost for Trigger Level 0.01 under the Scenario 1

\begin{tabular}{|lccc|}
\hline \multicolumn{1}{|c}{ Company } & Mean & St.Dev. & P-value \\
\hline Aluminum & 0.0122 & 0.0728 & 0.1324 \\
China Eastern & 0.1121 & 0.1152 & 0.0000 \\
China Life & 0.0115 & 0.0566 & 0.0691 \\
China Mobile & 0.0037 & 0.0540 & 0.5384 \\
China Petro and Chemical & 0.0203 & 0.0898 & 0.0440 \\
China Southern & 0.0928 & 0.0929 & 0.0000 \\
China Telcom & 0.0172 & 0.0570 & 0.0079 \\
China Unicom & 0.0493 & 0.1442 & 0.0027 \\
CNOOC & 0.0142 & 0.0549 & 0.0221 \\
Guangshen Railway & 0.0740 & 0.0886 & 0.0000 \\
Huaneng Power & 0.0335 & 0.0738 & 0.0001 \\
Petro China & 0.0025 & 0.0548 & 0.6823 \\
Sinopec Shanghai & 0.0526 & 0.0817 & 0.0000 \\
Yanzhou & 0.0363 & 0.0871 & 0.0003 \\
\hline
\end{tabular}

Table 4: Scenario 1, New York market open based on known HK close vs New York open, and HK open next day

This table presents the summary statistics for the monthly average returns on the equally weighted portfolio that consists of 14 pairs of dual-listings between 2002 and 2008 with or without transaction costs.

\begin{tabular}{|c|c|c|c|c|c|}
\hline & \multirow[b]{2}{*}{ Trigger level } & \multicolumn{2}{|c|}{ Without transaction costs } & \multicolumn{2}{|c|}{ With transaction cost } \\
\hline & & 0.01 & 0.02 & 0.01 & 0.02 \\
\hline \multirow[t]{12}{*}{ Monthly } & Average return & 0.0739 & 0.0412 & 0.038 & 0.0275 \\
\hline & Standard deviation & 0.0482 & 0.0404 & 0.0406 & 0.0335 \\
\hline & t-Statistics & 13.8903 & 9.2521 & 8.4724 & 7.4377 \\
\hline & Median & 0.0679 & 0.0314 & 0.0332 & 0.0224 \\
\hline & Skewness & 3.7445 & 4.7312 & 3.6857 & 4.9742 \\
\hline & Kurtosis & 24.5748 & 34.1485 & 25.663 & 37.2954 \\
\hline & Sharpe ratio & 1.5339 & 1.0217 & 0.9356 & 0.8214 \\
\hline & M2 (Modigliani RAP) & 0.1448 & 0.0965 & 0.0883 & 0.0775 \\
\hline & Min monthly return & -0.0147 & 0.0016 & -0.0476 & -0.0174 \\
\hline & Max monthly return & 0.3904 & 0.3321 & 0.309 & 0.2749 \\
\hline & Correlation with benchmark & -0.3524 & -0.3841 & -0.2771 & -0.3245 \\
\hline & Months with non-negative return & $99 \%$ & $100 \%$ & $94 \%$ & $93 \%$ \\
\hline \multirow[t]{6}{*}{ Individua } & Average return per trade & 0.0211 & 0.0309 & 0.0111 & 0.0209 \\
\hline & Average return of positive trade & 0.0315 & 0.0429 & 0.0265 & 0.0363 \\
\hline & Average return of negative trade & -0.0213 & -0.0256 & -0.0209 & -0.0268 \\
\hline & Total number of trades & 4163 & 1598 & 4163 & 1598 \\
\hline & Average holding time & 3.1446 & 3.4524 & 3.1446 & 3.4524 \\
\hline & Trades with excess return $>0$ & $80 \%$ & $83 \%$ & $67 \%$ & $76 \%$ \\
\hline
\end{tabular}

Standard deviations range between 2.92 per cent and 4.82 per cent. Further, an equalweighted portfolio of the underlying shares traded in HK and ADRs traded in New York of all 
14 companies are constructed, and used as a benchmark market. The equal-weighted portfolio has an average monthly return 0.88 per cent only and standard deviation 9.6 per cent.

\section{Table 5: Scenario 2, New York market close HK close vs New York close and HK open next day}

This table presents the summary statistics for the monthly average returns on the equally weighted portfolio that consists of 14 pairs of dual-listings between 2002 and 2008 with or without transaction costs.

\begin{tabular}{|c|c|c|c|c|c|}
\hline & \multirow[b]{2}{*}{ Trigger level } & \multicolumn{2}{|c|}{ Without transaction costs } & \multicolumn{2}{|c|}{ With transaction cost } \\
\hline & & 0.01 & 0.02 & 0.01 & 0.02 \\
\hline \multirow[t]{12}{*}{ Monthly } & Average return & 0.0598 & 0.0404 & 0.01 & 0.0148 \\
\hline & Standard deviation & 0.0398 & 0.0428 & 0.0386 & 0.036 \\
\hline & t-Statistics & 13.6189 & 8.5556 & 2.3532 & 3.7062 \\
\hline & Median & 0.0557 & 0.0318 & 0.0077 & 0.0115 \\
\hline & Skewness & 2.4874 & 3.4982 & 1.0062 & 2.5769 \\
\hline & Kurtosis & 12.9549 & 20.7876 & 8.8465 & 16.8963 \\
\hline & Sharpe ratio & 1.504 & 0.9448 & 0.2599 & 0.4093 \\
\hline & M2 (Modigliani RAP) & 0.142 & 0.0892 & 0.0245 & 0.0386 \\
\hline & Min monthly return & -0.0052 & -0.031 & -0.1001 & -0.0638 \\
\hline & Max monthly return & 0.2658 & 0.3059 & 0.178 & 0.2237 \\
\hline & Correlation with benchmark & -0.1471 & -0.2005 & 0.0407 & 0.0065 \\
\hline & Months with non-negative return & $99 \%$ & $99 \%$ & $63 \%$ & $71 \%$ \\
\hline \multirow[t]{6}{*}{$\overline{\text { Individua }}$} & Average return per trade & 0.0124 & 0.0162 & 0.0024 & 0.0062 \\
\hline & Average return of positive trade & 0.021 & 0.0266 & 0.0181 & 0.0234 \\
\hline & Average return of negative trade & -0.0134 & -0.0166 & -0.0144 & -0.017 \\
\hline & Total number of trades & 5800 & 3014 & 5800 & 3014 \\
\hline & Average holding time & 2.8714 & 2.9695 & 2.8714 & 2.9695 \\
\hline & Trades with excess return $>0$ & $75 \%$ & $76 \%$ & $52 \%$ & $57 \%$ \\
\hline
\end{tabular}

Most scenarios have reasonably high Sharpe ratio which exceed market benchmark Sharpe ratio of 0.096. Modigliani Risk-Adjusted Performance (RAP) as another measurement of risk is also used, which is derived from the Sharpe ratio and shows risk-adjusted return as well. Basically, the higher the Sharpe ratios number the better is the result, which suggests that the asset with the higher Sharpe ratio gives more return for the same risk.

Correlation analysis between the naive buy-and-hold strategy over the benchmark portfolio and an arbitrage-style trading strategy demonstrate that for all scenarios there is a low negative correlation with the benchmark or no correlation at all. That confirms a market neutrality of the proposed trading strategy. 
The most profitable scenarios are scenario 1 and scenario 4 with average monthly return of 3.8 per cent and 2.06 per cent based on the analysis of HK closing prices and trades executed with the shortest possible delay after HK closed. These results are consistent with the analysis of Granger causality and demonstrate that most of the trading action happens during trading session in HK, i.e. home market is dominant in price discovery (Lok and Kalev 2006).

\section{Table 6: Scenario 3, HK Market Open New York close vst HK open and New York open}

This table presents the summary statistics for the monthly average returns on the equally weighted portfolio that consists of 14 pairs of dual-listings between 2002 and 2008 with or without transaction costs.

\begin{tabular}{|c|c|c|c|c|c|}
\hline & \multirow[b]{2}{*}{ Trigger level } & \multicolumn{2}{|c|}{ Without transaction costs } & \multicolumn{2}{|c|}{ With transaction cost } \\
\hline & & 0.01 & 0.02 & 0.01 & 0.02 \\
\hline \multirow[t]{12}{*}{ Monthly } & Average return & 0.0468 & 0.0271 & 0.005 & 0.0103 \\
\hline & Standard deviation & 0.0343 & 0.0305 & 0.0292 & 0.023 \\
\hline & t-Statistics & 12.3442 & 8.0479 & 1.5351 & 4.0428 \\
\hline & Median & 0.0438 & 0.0225 & 0.0052 & 0.0083 \\
\hline & Skewness & 1.2339 & 2.5194 & 0.4956 & 1.741 \\
\hline & Kurtosis & 7.2595 & 12.0712 & 7.4569 & 11.5996 \\
\hline & Sharpe ratio & 1.3632 & 0.8887 & 0.1695 & 0.4465 \\
\hline & M2 (Modigliani RAP) & 0.1287 & 0.0839 & 0.016 & 0.0421 \\
\hline & Min monthly return & -0.045 & -0.0402 & -0.0971 & -0.0681 \\
\hline & Max monthly return & 0.182 & 0.1764 & 0.1262 & 0.1132 \\
\hline & Correlation with benchmark & -0.1988 & -0.2128 & -0.0556 & -0.0943 \\
\hline & Months with non-negative return & $98 \%$ & $94 \%$ & $62 \%$ & $76 \%$ \\
\hline \multicolumn{2}{|c|}{ Individual Average return per trade } & 0.0113 & 0.016 & 0.0013 & 0.006 \\
\hline & Average return of positive trade & 0.029 & 0.0367 & 0.0255 & 0.0321 \\
\hline & Average return of negative trade & -0.0247 & -0.0299 & -0.0255 & -0.0311 \\
\hline & Total number of trades & 4870 & 1978 & 4870 & 1978 \\
\hline & Average holding time & 2.9811 & 3.2209 & 2.9811 & 3.2209 \\
\hline & Trades with excess return $>0$ & $67 \%$ & $69 \%$ & $53 \%$ & $59 \%$ \\
\hline
\end{tabular}

Mispricing between the underlying shares and ADRs during HK trading session probably will not be fixed on the trading in New York, so the investor has enough time to open positions on both markets and profit from that mispricing. 


\section{Table 7: Scenario 4, HK Market Close New York lose vs HK close and New York open}

This table presents the summary statistics for the monthly average returns on the equally weighted portfolio that consists of 14 pairs of dual-listings between 2002 and 2008 with or without transaction costs.

\begin{tabular}{llccccc} 
& & Without transaction costs & & \multicolumn{2}{c}{ With transaction cost } \\
\cline { 2 - 3 } \cline { 5 - 6 } Trigger level & 0.01 & 0.02 & & 0.01 & 0.02 \\
\hline Monthly & Average return & 0.0883 & 0.0693 & & 0.0206 & 0.0244 \\
& Standard deviation & 0.039 & 0.0383 & & 0.0347 & 0.0295 \\
t-Statistics & 20.5064 & 16.3597 & & 5.3869 & 7.4962 \\
Median & 0.0807 & 0.0595 & & 0.018 & 0.0197 \\
Skewness & 1.2104 & 1.8195 & & 0.3928 & 1.132 \\
Kurtosis & 7.7086 & 8.5765 & & 6.9314 & 8.2275 \\
Sharpe ratio & 2.2646 & 1.8066 & & 0.5949 & 0.8278 \\
M2 (Modigliani RAP) & 0.2138 & 0.1706 & & 0.0562 & 0.0782 \\
Min monthly return & -0.0236 & 0.0081 & & -0.0901 & -0.0499 \\
Max monthly return & 0.2644 & 0.2532 & & 0.1622 & 0.161 \\
Correlation with benchmark & -0.3366 & -0.3674 & & -0.2158 & -0.2445 \\
Months with non-negative return & $99 \%$ & & $100 \%$ & & $82 \%$ & $90 \%$ \\
\hline Individual Average return per trade & 0.0131 & 0.0155 & & 0.0031 & 0.0055 \\
Average return of positive trade & 0.0172 & 0.0197 & & 0.0137 & 0.0157 \\
Average return of negative trade & -0.0106 & -0.0112 & & -0.0098 & -0.0102 \\
Total number of trades & 7847 & 5221 & & 7847 & 5221 \\
Average holding time & 2.3921 & 2.4465 & & 2.3921 & 2.4465 \\
Trades with excess return $>0$ & $85 \%$ & & $86 \%$ & & $55 \%$ & $61 \%$ \\
\hline
\end{tabular}

\section{Conclusion}

Arbitrage strategy is a well-known international finance topic relating to trades in the world's biggest currency markets. The review of literature suggests that, in regard to the law of one price in the trading of share-like instruments, the results on the LOP is very mixed. Hence the motivation of this study to conduct a longitudinal study of 14 major China firms, listed and traded in Hong Kong and in New York (as ADRs). The issue examined is whether there is arbitrage such that the trading of these 14 shares in three markets in different currencies are arbitrage-free, meaning that the prices are not significantly different.

In practice, arbitrage which is technically riskless will still involve a certain level of risk due to uncertain future cash flows (dividends), trading risks, and so on (Kleinbard et al. 1993). 
Under certain circumstances, most of the Chinese ADRs that are traded in the US markets do offer better gaps comparing their underlying asset prices traded in Hong Kong. Hence, arbitrageurs could pocket a profit. However there is inherent risk when conducting this strategy. The execution of the arbitrage might take longer time than an arbitrageur expects. In an ideal world, trades placed to capture an arbitrage opportunity would be instantaneously executed. However, in practice, execution takes time, especially for ADRs trading and in two nonoverlapping markets. In most cases, price variations between the time when an arbitrage opportunity is entered into and the time when the trade is actually executed might differ greatly. Further, some of the ADRs might not be very liquid. Therefore, establishing the long position in the US market might not be possible.

We therefore attempted to ascertain if price parity is maintained between the dual-listed Chinese shares traded in Hong Kong and New York. Studies have shown that these identical assets may be traded freely across international borders; arbitrage trading by investors should ensure such asset prices will not differ by more than the transaction costs involved. The two markets of Hong Kong and New York in terms of dual-listed shares appear to confirm LOP reasonable well. However, price disparities do exist, and so do the arbitrage opportunities.

It might be asked why there are so many profitable disequilibria in these two developed markets. The possible explanation is the non-overlapping trading time. However, when the price disparity becomes greater, the large price difference gap would be arbitraged away immediately. Although the overnight risk makes the arbitrage difficult, the empirical results in this study show the monthly return ranging from 0.5 per cent to 3.8 per cent could be obtained for this simple strategy when transaction costs are considered. This evidence could be taken as possibly arising from data deficiency or method deficiency or that it is simply that these 14 stock prices are inefficiently priced across borders. Either way, the law of one price appears to be violated in the trades of these otherwise very liquid and visible Chinese shares, although in exchange rate studies, there is more evidence of arbitrage-free trades in major currencies.

Author information: The submitting author is Dr Bogomolov and he may be contacted at his Email address Timofei.bogomolov@unisa.edu.au. The co-author is Lixian Liu with the E-mail address of Lixian.Liu@unisa.edu.au. Both are staff members at the University of South Australia. 


\section{References:}

Alves, M. V. B., and Matthew R. M., (2003). Intraday Arbitrage in Emerging market American Depositary Receipts. unpublished working paper.

Amary, Beatriz, and Otavio Ottoni, (2006). ADR arbitrage opportunities for dummies. Unpublished working paper.

Bailey, W., Chung, P., and Kang, J., (1999). Foreign Ownership Restrictions and Equity Price Premiums: What Drives the Demand for Cross-border Investments?, Journal of Financial and Quantitative analysis, 34: 489-511.

Bowen, D., Hutchinson, M. C.. and O'Sullivan N., (2010). High Frequency Equity Pairs Trading: Transaction Costs, Speed of Execution and Patterns in Returns. Journal of Trading, Forthcoming.

Cai, H., (2007). Bonding, law enforcement and corporate governance in China. Stanford Journal of Law, Business \& Finance 13: 82-111.

De Jong, L. R., and A. Van Dijk, M., (2009). The risk and return of arbitrage in dual-listed c ompanies. Review of Finance 13: 495-520.

Ding, D. K., (2000). Price parities of stocks listed on both the Kuala Lumpur stock exchange and Singapore's CLOC international. Advances in Pacific Basin Financial Market, 21-44.

Do, B, (2009). Are Pairs Trading Profits Robust to Trading Costs?, Unpublished working paper.

Domowitz, I., Glen, J., and Madhavan, A., (1998). International cross-listing and order flow migration: evidence from an emerging market. Journal of Finance 53: 2001-2027.

Gande, A., (1997). American Depositary Receipts: Overview and Literature Survey. Financial Markets, Institutions \& Instruments 6: 61-83.

Gatev, E., Goetzmann, W.N., and Rouwenhorst, K.G., (2006). Pairs Trading: Performance of a Relative-Value Arbitrage Rule. Review of Financial Studies, 19: 797-827.

Han, B., (2004). Limits of arbitrage, sentiment and pricing kernel: Evidences from index options. unpublished working paper.

Hsu, J., and Wang, Hsin-Yi, (2008). Why do price spreads between domestic shares and their ADRs vary over time?. Pacific Economic Review 13: 473-491.

Kato, K., Linn, S., and Schallheim, J. (1991). Are there arbitrage opportunities in the market for American Depository Receipts? Journal of International Financial Markets, Institutions \& Money 73: 13-32.

Kaul, A., and MEhrotra, V., (2000). In search of international integration: an examination of intra-daily North American trading of Canadian dually listed stocks. Working Paper, University of Alberta.

Kim, M.,. Szakmary, A.C., and Mathur, I., (2000), Price transmission dynamics between ADRs and their underlying foreign securities. Journal of Banking and Finance 24: 1359-1382.

Kleinbard, E.D., Clearly, G., and Hamilton, S., (1993). Risk and riskless positions in securities. Taxes, 783-799.

Lau, S.T., Diltz, J. D., and Apilado, V.P., (1994). Valuation effects on international stock exchange listings. Journal of Banking and Finance 18: 743-755.

Lok, E., and Kalev, P., (2006). The intraday price behaviour of Australian and New Zealand cross-listed stocks. International Review of Financial Analysis 15: 377-397.

Mak, B.S.C., and Ngai, A.M.S., (2005). Market linkage for dual-listed Chinese stocks. The Chinese Economy 38: 88-107.

Maldonado, R.,, and Saunders, A., (1983). Foreign exchange restrictions and the Law of One Price. Financial Management, 12: 19-23.

Malkiel, B.G., (2007). The efficiency of the Chinese Stock Markets: Some unfinished business on the road to economic transformation. CEPS working paper No. 154.

Miller, D.P., and Morey, M.R., (1996). The intraday pricing behaviour of international dually 
listed securities. Journal of International Financial Markets, Institutions and Money 6: 7989.

Park J., and Tavakkol, A., (1994). Are ADRs a dollar translation of their underlying securities? The case of Japanese ADRs. Journal of International Financial Markets, Institutions and Money 4: 77-87.

Pontiff, J., (2006). Costly arbitrage and the myth of idiosyncratic risk. Journal of Accounting and Economics 42: 35-52.

Suarez, E. D., (2005). Arbitrage opportunities in the Depositary Receipts market: Myth or reality?. Journal of International Financial Markets, Institutions and Money 15: 469-480.

Wahab, M., Lashgari, M., and Cohn, R., (1992). Arbitrage opportunities in the American Depository Receipts market revisited. Journal of International Financial Markets, Institutions and Money 2: 97-130. 